\title{
100-YEAR-OLD HAEMATOLOGICA IMAGES: THE QUARREL ABOUT THE ORIGIN OF PLATELETS (II)
}

\section{Carlo L. Balduini}

Ferrata-Storti Foundation, Pavia, Italy

E-mail: CARLOL.BALDUINI - carlo.balduini@unipv.it

doi:10.3324/haematol.2020.254011

A t the time of the birth of Haematologica in 1920, the origin of platelets was still a hotly debated topic, as demonstrated by the observation that five of the 31 articles published in the first volume of the journal dealt with the genesis of these corpuscles.

The cover of this issue of Haematologica has been taken from one of the figures of the article entitled "Facts and hypotheses on the origin of platelets" published in Haematologica in 1923 by Antonio Cesaris Demel, Professor of Pathology at the University of Pisa, Italy. ${ }^{2}$ The author stimulated megakaryopoiesis in cats with 'fairly rapid asphyxiation' of the animals, and then studied sections of their spleens stained with Giemsa. Cesaris Demel observed that, on stimulation of megakaryopoiesis, megakaryocytes migrate to the vessel, introduce pseudopods into the vascular wall, and sometimes pass in their entirety into the lumen of the vessel. During this process, platelets detach from the surface of the cell in contact with blood. These findings of Cesaris Demel seem to confirm the hypothesis formulated in 1906 by Wright that platelets are produced from megakaryocytes. ${ }^{3}$ However, unexpectedly, the author concluded that they are not fragments of megakaryocytes, but instead derive from a not clearly defined plasma component that precipitates in contact with the surface of megakaryocytes "as", he wrote, "fibrin is formed by precipitation of plasma components under specific conditions".

Although this conclusion was wrong, the Cesaris Demel drawings are extraordinary because they describe proplatelet formation exactly as we know it occurs today after nearly a century of studies with increasingly sophisticated technologies. ${ }^{4}$ As already discussed in previous comments to old Haematologica images, knowledge of blood cells a century ago, obtained almost exclusively by observing blood and tissues under a microscope, was much more advanced than is commonly believed.

\section{References}

1. Mazzarello P. One hundred years of Haematologica. Haematologica. 2020;105(1):12-21.

2. Cesaris Demel A. [Fatti ed ipotesi sulla origine delle piastrine]. Haematologica. 1924;5:104-146.

3. Wright JH. The origin and nature of the blood plates. Boston Medic. Surg. J. 1906;154:643-645

4. Italiano JE Jr, Lecine P, Shivdasani RA, Hartwig JH. Blood platelets are assembled principally at the ends of proplatelet processes produced by differentiated megakaryocytes. J Cell Biol. 1999;147(6):1299-1312.
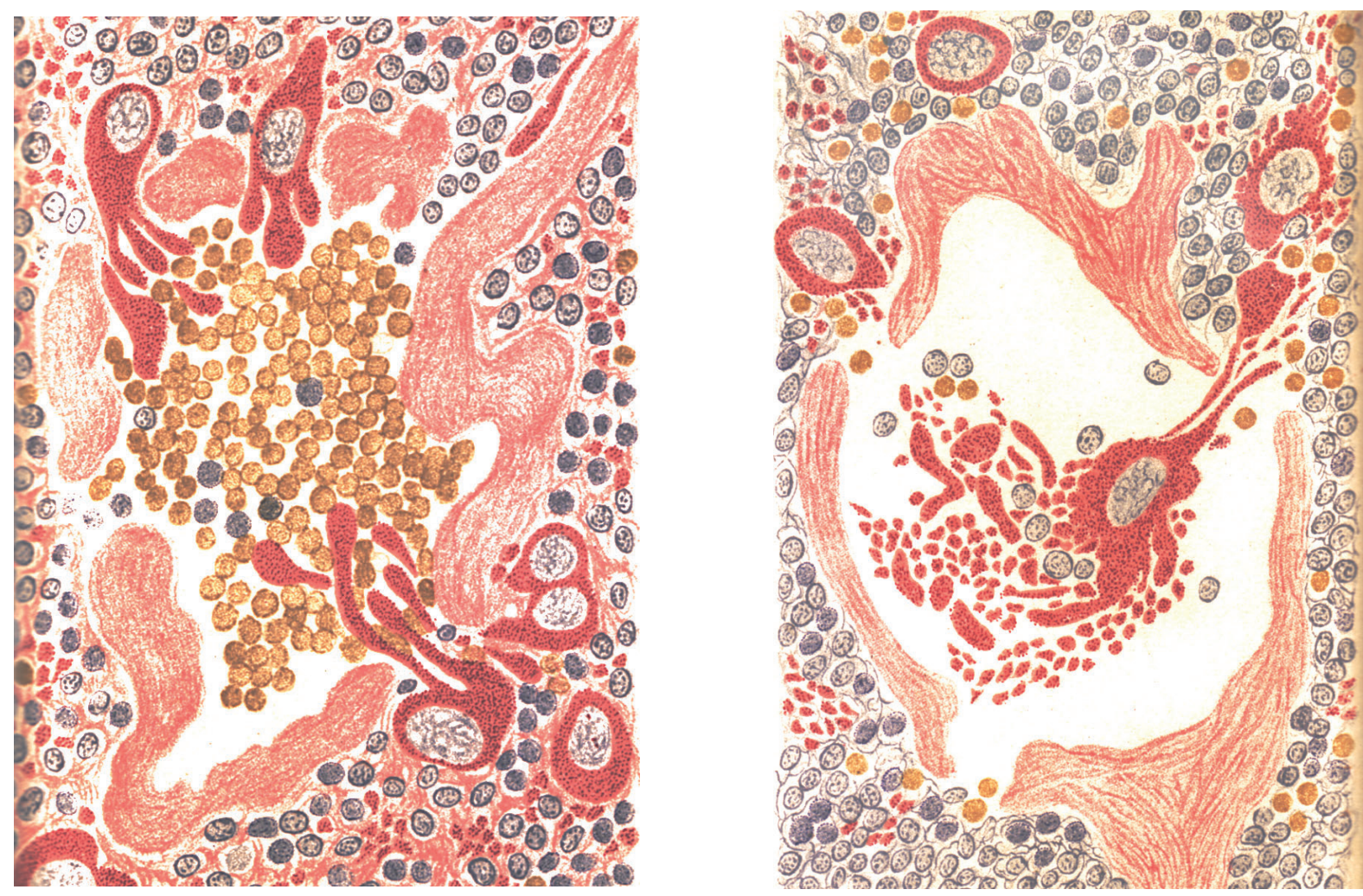

Figure 1. Platelet formation in cat spleen as described by Cesaris Demel in Haematologica in 1923. The introduction of long and thin protrusions of megakaryocytes into the lumen of vessel, as well as the migration of the entire megakaryocyte into the vessel, has been 'rediscovered' only recently. 